\title{
Vascular endothelial growth factor expression and their action in the synovial membranes of patients with painful knee osteoarthritis
}

\author{
Shotaro Takano ${ }^{1}$, Kentaro Uchida ${ }^{1 *} \mathbb{D}$, Gen Inoue ${ }^{1}$, Toshihide Matsumoto², Jun Aikawa', Dai Iwase1,
} Manabu Mukai ${ }^{1}$, Masayuki Miyagi ${ }^{1}$ and Masashi Takaso ${ }^{1}$

\begin{abstract}
Background: Research suggests that vascular endothelial growth factor (VEGF) levels in the synovial fluid of knee osteoarthritis (KOA) patients are positively correlated with KOA severity. The relationship between synovial VEGF levels and pain in human KOA patients is not fully understood, and the role of VEGF in the pain pathway remains unclear.

Methods: We harvested synovial membrane (SM) from 102 patients with radiographic evidence of KOA (unilateral Kellgren/Lawrence [K/L] grade 2-4) during total knee arthroplasty. Patients scored their pain on a 0 to $10 \mathrm{~cm}$ visual analog scale (VAS). VEGF levels in the SM of KOA patients with strong/severe (VAS $\geq 6$ ) and mild/moderate pain (VAS $<6)$ were compared. Correlations between VAS and VEGF mRNA expression were investigated. To investigate a possible mechanism for VEGF-induced pain, the distribution of VEGF and the neuropeptide apelin was determined by immunohistochemical analyses. To investigate the role of VEGF in regulating apelin expression, SM cells were exposed to VEGF.

Results: VEGF expression in the VAS $\geq 6$ group was significantly greater than expression in the VAS $<6$ group. Expression levels of VEGF were also positively correlated with VAS. VEGF-positive cells were identified in the lining of the SM. Expression of apelin mRNA and protein were significantly elevated in SM cells treated with exogenous VEGF compared to those treated with vehicle.
\end{abstract}

Conclusion: Synovial VEGF may be involved in pain pathways in KOA and its action may be mediated by apelin.

Keywords: Vascular endothelial growth factor, Synovial membrane, Pain, Osteoarthritis, Neuropeptides

\section{Background}

Osteoarthritis $(\mathrm{OA})$ is the most common form of arthritis and a leading cause of disability worldwide. This disability is largely due to pain, a major symptom of the condition. Pain contributes to functional limitations and reduces quality of life [1-4]. Largely because of pain, lower extremity $\mathrm{OA}$ is well recognized as the leading cause of mobility impairment in older adults [5]. Pharmacologic treatment options for OA are centered around the relief of pain and support for functional improvement in

\footnotetext{
* Correspondence: kuchida@med.kitasato-u.ac.jp

${ }^{1}$ Department of Orthopedic Surgery, Kitasato University School of Medicine,

1-15-1 Minami-ku Kitasato, Sagamihara City 252-0374, Japan

Full list of author information is available at the end of the article
}

patients. Nevertheless, the efficacy of treatments such as nonsteroidal anti-inflammatory drugs (NSAIDs) can be limited, and can cause significant adverse effects such as cardiorenal and gastrointestinal toxicity $[6,7]$. It is therefore important to establish the mechanisms underlying OA pain to aid in drug development for OA treatment.

Vascular endothelial growth factor (VEGF) is a potent stimulator of angiogenesis, and also a contributor to inflammation. VEGF in OA patients has been found to be elevated in the synovial membrane (SM) [8-11], subchondral bone [12-14], synovial fluid (SF) [15-18], serum [16-19], and articular cartilage [20-28]. In particular, VEGF is strongly expressed in synovial lining cells in OA patients [29]. Intraarticular injection of anti-VEGF antibody reduced

(c) The Author(s). 2018 Open Access This article is distributed under the terms of the Creative Commons Attribution 4.0 International License (http://creativecommons.org/licenses/by/4.0/), which permits unrestricted use, distribution, and reproduction in any medium, provided you give appropriate credit to the original author(s) and the source, provide a link to the Creative Commons license, and indicate if changes were made. The Creative Commons Public Domain Dedication waiver (http://creativecommons.org/publicdomain/zero/1.0/) applies to the data made available in this article, unless otherwise stated. 
synovial inflammation in a rabbit OA model [30]. Several studies have suggested that SF and plasma VEGF concentrations in OA patients correlate with OA severity [16, 17]. In addition, recent studies have reported that VEGF contributes to pain in a rodent neuropathic pain model [31-34] and cancer pain model [35]. The exact relationship between VEGF expression in SM and pain in human KOA patients is not fully understood.

Recent studies have suggested that several neuropeptides, such as calcitonin gene-related peptide (CGRP) and nerve growth factor (NGF), in the SM are involved in the OA pain pathway [36-39]. Apelin is a recognized member of the adipose-secreted cytokine family and is initially secreted as a pre-propeptide of 77 amino acid residues, which is then cleaved into a number of active forms [40]. The apelin signaling pathway was shown to play a major role in the development of the functional vascular network [41] and apelin expression was elevated in endothelial cell culture following VEGF stimulation [42]. Several studies also showed that apelin can regulate peripheral pain sensitivity mediated by apelin receptors (APJ) and GABAA receptors [21, 43]. Hu et al. reported that apelin concentration in SF is increased in OA patients [44]. These observations led us to investigate the role of VEGF in regulating apelin in SM and its contribution to the OA pain pathway.

We investigated the relationship between VEGF expression in SM and pain in knee osteoarthritis (KOA) patients. In addition, we investigated whether VEGF regulates apelin expression in the SM.

\section{Methods}

\section{Patients}

This study was approved by the Institutional Review Board for Clinical Research and Treatment in Kitasato University (approval No. B13-113). Sample size was determined with a power analysis for an alpha of 0.05 and power of 0.80 using G*POWER3. Patients scored their pain on a 0 to $10 \mathrm{~cm}$ visual analog scale (VAS). Power analysis showed that 44 SM samples of patients with VAS $<6$ and 58 SM samples of patients with VAS $\geq 6$ were required to identify a difference in VEGF expression between the two groups. SM samples were harvested from
102 patients undergoing total knee arthroplasty. The study enrolled 22 men and 80 women (age $46-89$ years, mean \pm standard error $(\mathrm{SE})=73.2 \pm 0.8$ years; body mass index (BMI) range 18.4-36.7, mean $\pm \mathrm{SE}=26.0 \pm 0.4 \mathrm{~kg} / \mathrm{m}^{2}$ ) with radiographic evidence of KOA (unilateral Kellgren/ Lawrence [K/L] grades 2 (3/102, 2.9\%), 3 (36/102, 35.3\%) and $4(63 / 102,61.8 \%))$. All patients provided informed consent for participation in this study 1 day before surgery. SM samples were harvested intraoperatively from the suprapatellar pouch of each operated knee and immediately stored frozen in liquid nitrogen at $-80{ }^{\circ} \mathrm{C}$ until required for extraction of RNA. SM samples obtained from six patients were used for cell culture. The remaining samples were fixed in $4 \%$ paraformaldehyde phosphate-buffered solution (Nacalai Tesque, Kyoto, Japan) for $72 \mathrm{~h}$ for use in histological analysis.

\section{Quantitative polymerase chain reaction (qPCR) analysis}

Extraction of total RNA from SM and cultured SM cells and cDNA synthesis was conducted as reported previously [45]. PCR primer pair sequences for use in $\mathrm{PPCR}$ analysis were: VEGF-Forward (5' - TTGCCTTGCTGCTCTACCT C-3') and VEGF-Reverse (5'- AGCTGCGCTGATAG ACATCC-3') for VEGF amplification (product size: 117 bp); apelin-Forward (5'- GAATCTGCGGCTCT GCGT-3') and apelin-Reverse (5' - CATCAGGGACCCTC CACACA-3') for apelin amplification (product size: 76 bp); and GAPDH-Forward (5' ${ }^{\prime}$-TGTTGCCATCAATGACCCC TT-3') and GAPDH-Reverse (5'-CTCCACGACGTACT CAGCG-3') for GAPDH amplification (product size: $223 \mathrm{bp}$ ). Specificity of the qPCR products was evaluated using melting curve analysis. Relative mRNA expression levels of VEGF and apelin were evaluated using qPCR (CFX-96 ${ }^{\circ}$, Bio-Rad, Richmond CA, USA). Expression levels of VEGF and apelin mRNA were normalized to the expression of the housekeeping gene, GAPDH.

Expression levels of VEGF mRNA were compared between the strong/severe (VAS $\geq 6$ ) and mild/moderate pain (VAS $<6$ ) groups (Table 1 ), using VAS $=6$ as a cutoff based on previous reports [39, 46, 47]. The correlation between VAS levels and VEGF mRNA expression was also determined. Relative VEGF expression was calculated based on the mean of all samples of the VAS $<6$ group.

Table 1 Characteristics of patients in VAS $<6$ and VAS $\geq 6$ groups

\begin{tabular}{lll}
\hline Characteristic & VAS $<6(n=44)$ & VAS $\geq 6(n=58)$ \\
\hline Age $(\mathrm{y})$ & $74.2 \pm 1.1$ & $72.3 \pm 1.2$ \\
Male/Female, $\mathrm{n}$ & $12 / 32$ & $10 / 48$ \\
$\mathrm{BMI}\left(\mathrm{kg} / \mathrm{m}^{2}\right)$ & $25.5 \pm 0.6$ & $26.3 \pm 0.6$ \\
Number of patients with Kellgren/Lawrence grade 2, 3, 4 & $3,14,27$ & $0,22,36$ \\
VAS $(\mathrm{cm})$ & $3.7 \pm 0.2$ & $8.4 \pm 0.2$ \\
\hline
\end{tabular}

Data are mean \pm standard error unless otherwise indicated

$B M I$ body mass index, VAS visual analogue pain scale 
To investigate the relationship between VEGF and K/L grades, the 102 knee OA patients were divided into three groups based on their K/L grade (2, 3, or 4). The clinical characteristics of patients in each of these groups are shown in Table 2. Relative VEGF expression was calculated based on the mean of all samples of the K/L2 group.

\section{Immunohistochemistry}

Following fixation, SM samples were embedded in paraffin, sectioned at $3 \mu \mathrm{m}$ thickness, then deparaffinized (Clear Plus ${ }^{\oplus}$, FALMA, Tokyo, Japan) and pretreated with sodium citrate buffer ( $\mathrm{pH}$ 6.0) containing $0.1 \%$ polyoxyethylene sorbitan monolaurate (Nacalai Tesque, Kyoto, Japan) at $98{ }^{\circ} \mathrm{C}$ for $20 \mathrm{~min}$ for antigen retrieval. The sections were subsequently washed three times with phosphate-buffered saline for $5 \mathrm{~min}$ and incubated with rabbit polyclonal anti-VEGF antibody (1:100 dilution; Santa Cruz Biotechnology Inc., Santa Cruz CA, USA) and mouse monoclonal anti-apelin antibody (1:100 dilution; Santa Cruz Biotechnology) for $4 \mathrm{~h}$ at $4{ }^{\circ} \mathrm{C}$. The sections were additionally incubated with Alexa 488 Fluor $^{\circ}$-conjugated goat anti-rabbit IgG antibody (1:100 dilution; Thermo Fisher Scientific, Waltham MA, USA) and Alexa 594 Fluor-conjugated goat anti-mouse IgG antibody (1:100 dilution; Thermo Fisher Scientific) for $1 \mathrm{~h}$ at room temperature. The distribution of fluorescence in SM sections was analyzed using a fluorescence microscope (Axiovert $200^{\circ}$, Zeiss, Jena, Germany).

\section{Synovial membrane cell culture}

Synovial membrane cells (SMCs) were isolated from $500 \mathrm{mg}$ SM using $40 \mathrm{~mL}$ of a $1 \mathrm{mg} / \mathrm{mL}$ collagenase solution. The SMCs were incubated in $\alpha$-minimal essential media ( $\alpha$-MEM; Nacalai Tesque) containing $10 \%$ fetal bovine serum in six-well plates. After 1 week, the SMCs were incubated with vehicle (serum free $\alpha$-MEM) or 10 or $100 \mathrm{ng} / \mathrm{mL}$ human recombinant VGEF (Biolegend, San Diego CA, USA) for $24 \mathrm{~h}$. Subsequently, total mRNA and protein were extracted and used in western blotting and qPCR analysis. Relative expression was calculated based on the mean of all samples of the vehicle-treated group.

\section{Western blotting for apelin}

To investigate the regulation of apelin by VEGF, SMCs harvested from six patients were stimulated with $1 \mathrm{ng} / \mathrm{mL}$

Table 2 Clinical characteristics of patients ( $K / L$ 2, 3 and 4)

\begin{tabular}{llll}
\hline Characteristic & $\mathrm{K} / \mathrm{L} 2(n=3)$ & $\mathrm{K} / \mathrm{L} 3(n=36)$ & $\mathrm{K} / \mathrm{L} 4(n=63)$ \\
\hline Age $(\mathrm{y})$ & $72.0 \pm 2.6$ & $72.0 \pm 4.2$ & $73.9 \pm 8.4$ \\
Male/Female, $\mathrm{n}$ & $1 / 2$ & $9 / 27$ & $12 / 51$ \\
$\mathrm{BMI}\left(\mathrm{kg} / \mathrm{m}^{2}\right)$ & $25.8 \pm 3.4$ & $26.4 \pm 4.3$ & $25.7 \pm 4.1$ \\
VAS $(\mathrm{cm})$ & $3.7 \pm 2.5$ & $6.9 \pm 2.6$ & $6.2 \pm 2.6$ \\
\hline
\end{tabular}

Data are mean \pm standard error unless otherwise indicated $B M I$ body mass index, VAS visual analogue pain scale, $K / L$ Kellgren/Lawrence grade or $10 \mathrm{ng} / \mathrm{mL}$ VEGF for $24 \mathrm{~h}$. Using methodology described elsewhere [48], SMCs were lysed in radioimmunoprecipitation buffer (Thermo Fisher Scientific) containing a protease inhibitor cocktail (Sigma-Aldrich, St. Louis MO, USA). Protein concentration was determined for each cell extract using a bicinchoninic acid (BCA) assay (Thermo Fisher Scientific). A total of $30 \mu \mathrm{g}$ of each protein was separated by sodium dodecyl sulfate-polyacrylamide gel electrophoresis and electrophoretically transferred to polyvinyl difluoride membranes. These membranes were then blocked with polyvinylidene fluoride (PVDF) blocking reagent (DS Pharma Biomedical, Suita, Japan) for $1 \mathrm{~h}$ and incubated overnight at $4{ }^{\circ} \mathrm{C}$ with mouse monoclonal primary antibody against apelin (1:200 dilution; Santa Cruz Biotechnology Inc.). The membranes were washed with Tris-buffered saline containing 0.05\% Tween and then incubated with horseradish peroxidase-conjugated anti mouse IgG (1:1000 dilution; GE Healthcare, Piscataway NJ, USA). Apelin proteins were visualized by chemiluminescence using an enhanced chemiluminescence detection system (GE Healthcare) and exposure of the membranes to $\mathrm{x}$-ray film. Bands were quantified by densitometric scanning using ImageJ software (NIH, Bethesda MD, USA). Densitometry levels of apelin proteins were normalized against that of $\beta$-actin.

\section{Statistical analysis}

Differences in VEGF expression between the VAS $<6$ and VAS $\geq 6$ groups were compared using the Mann-Whitney $U$-test. Differences in VEGF expression among K/L2, 3 and 4 subjects were compared using the Kruskal-Wallis test. Tukey's multiple comparisons test was used to compare vehicle control and VEGF-treated cells. The relationship between VEGF expression and VAS was evaluated using Spearman's correlation coefficient. All statistical analyses were conducted using SPSS software (v. 19.0; SPSS, Chicago IL, USA), with a $P$ value $<0.05$ considered statistically significant for all analyses.

\section{Results}

\section{Relationship between VEGF expression and VAS}

The VAS $\geq 6$ and VAS $<6$ groups did not differ with regard to patient age, male/female ratio, BMI, or KL 2/3/4 ratio (Table 1). qPCR analysis showed that VEGF expression in the SM was significantly higher in the VAS $\geq 6$ group than the VAS $<6$ group (Fig. 1a, $P<0.05$ ). VEGF levels were also positively correlated with VAS (Fig. $1 b, \rho=0.346, P<0.05$ ).

\section{Relationship between VEGF expression and K/L grades}

The three K/L grade groups did not differ with regard to patient age, male/female ratio, BMI, or VAS (Table 2). There was no difference in synovial VEGF expression among the K/L2, 3 and 4 groups (Fig. 2). 
$\mathbf{a}$

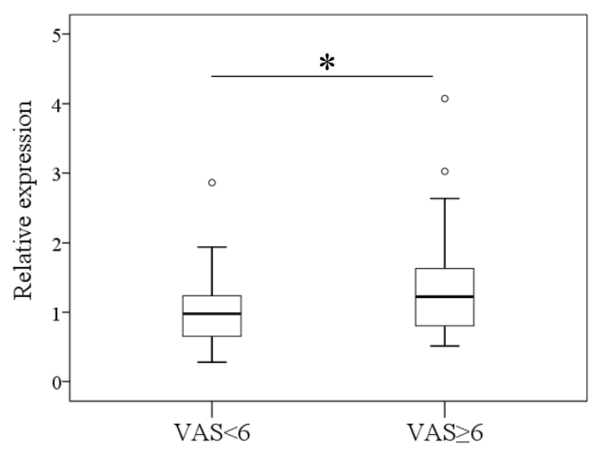

b

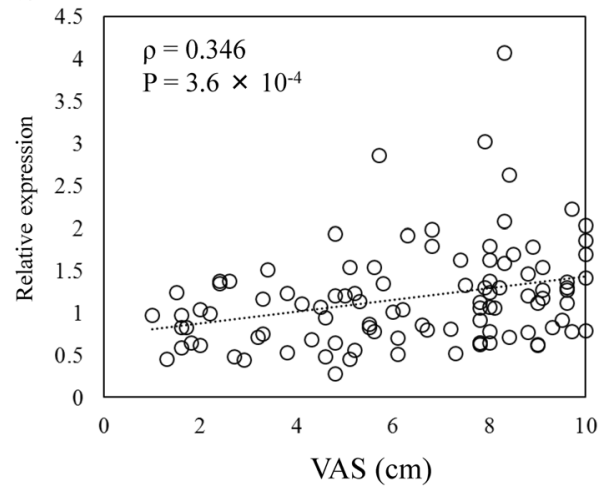

Fig. 1 qPCR analysis of VEGF expression in the synovial membranes (SMs) of knee osteoarthritis (KOA) patients according to their VAS score. a "Box and whisker" plot of VEGF expression in the SMs of KOA patients with mild/moderate (VAS $<6)(n=44)$ and strong/severe pain (VAS $\geq 6)$ $(n=58)$. The plot shows the median values (bold horizontal line), interquartile range (IQR) (box), and range. Outliers beyond 1.5-fold of the IQR from the box are plotted. * $P=0.008$. VAS, visual analog scale. b Scatter plot showing the correlation between VAS scores and VEGF levels.

Relative expression was calculated based on the mean of all samples of the VAS $<6$ group

\section{Distribution of VEGF and apelin in the SMs of KOA patients}

Immunohistochemical analysis was conducted to investigate the distribution of VEGF and apelin in the SMs of KOA patients (Fig. 3). Immunostaining showed that VEGF and apelin protein were both expressed in the synovial lining layers (Fig. 3).

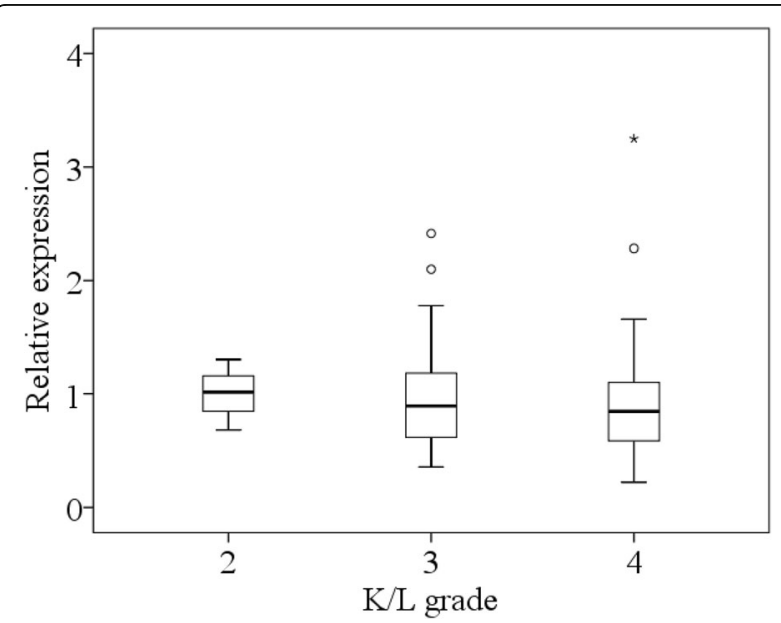

Fig. 2 Relationship between VEGF mRNA expression level and Kellgren/Lawrence $(K / L)$ grade. To investigate the relationship between VEGF and K/L grades, 102 knee OA patients were divided into three groups according to their $K / L$ grade $(2,3$, or 4$)$. The three groups did not differ by patient age, male/female ratio, body mass index, or pain score based on the visual analog scale. Relative expression was calculated based on the mean of all samples of the KL2 group. The plot indicates median (bold horizontal line), interquartile range (IQR) (box), and range. Outliers beyond 1.5-fold of the IQR from the box are plotted
Effects of VEGF on apelin expression in SMCs

qPCR analysis showed that the expression of apelin mRNA increased significantly in SMCs following 10 and $100 \mathrm{ng} / \mathrm{mL}$ VEGF stimulation (1.73-fold and 1.69-fold, respectively, $P<0.05$; Fig. 4). Western blotting analysis showed that the expression of apelin was significantly increased in SMCs in the presence of exogenously added 10 and $100 \mathrm{ng} / \mathrm{mL}$ VEGF (1.85-fold and 1.56-fold, respectively, $P<0.05$; Fig. 5a and b).

\section{Discussion}

In the SM of KOA patients, VEGF mRNA expression in the VAS $\geq 6$ group was significantly higher than that in the VAS $<6$ group. VEGF and apelin were both expressed in the synovial lining layers and VEGF stimulated apelin mRNA and protein expression in SM cell culture. Together, these findings indicate that VEGF expression in SM may be involved in knee pain via apelin in KOA patients.

Several studies have reported that VEGF may contribute to chronic pain conditions [31, 32, 49]. Injection of VEGF in spinal cord-injured rats causes mechanical allodynia [49]. VEGF neutralization in rat chronic constriction injury (CCI) models attenuates chronic pain behavior by reducing the VEGF receptor expression level in dorsal root ganglia to inhibit neuropathic pain signaling [32]. Perineural injection of a VEGF inhibitor inhibited tactile allodynia and thermal hyperalgesia caused by partial sciatic nerve ligation [31]. Here, KOA patients who experienced severe/strong pain showed increased VEGF expression levels in SM. These findings suggest that synovial VEGF seems to play an important role in the pain pathway associated with KOA.

Several studies have reported that VEGF regulates apelin expression in vitro and in vivo [42, 50, 51]. VEGF 

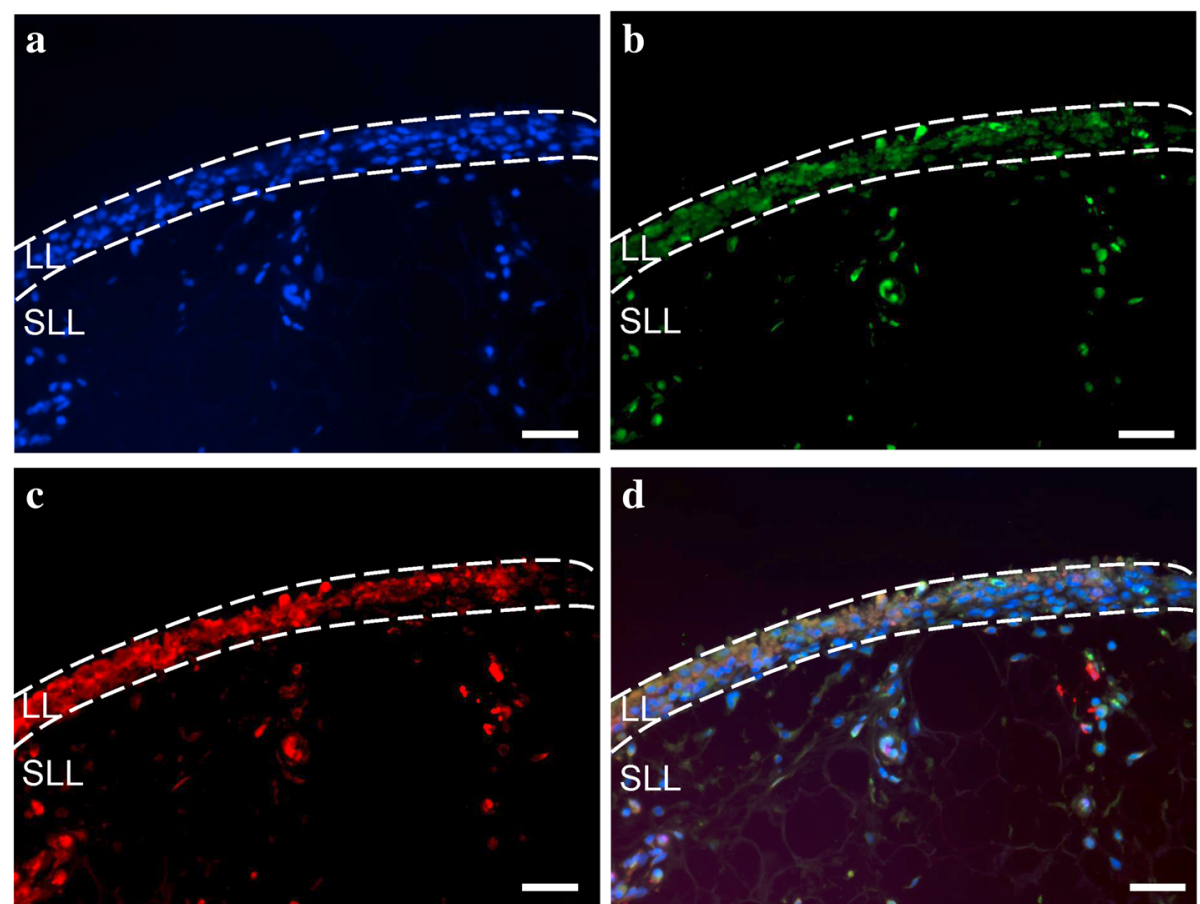

Fig. 3 Immunostaining of VEGF and apelin in the synovial membranes of knee OA patients. Synovial membranes stained with a DAPI (nuclei), $\mathbf{b}$ VEGF, or $\mathbf{c}$ apelin. $\mathbf{d}$ The merged images. Region enclosed by dotted lines indicates the lining layer (LL), which is above the sublining layer (SLL) in the synovial membrane. Scale bar $=100 \mu \mathrm{m}$

stimulates apelin mRNA in human umbilical venous endothelial cells in vitro [50]. Local injection of bevacizumab, an anti-VEGF antibody, inhibits apelin expression in monkeys with occlusion of the central retinal vein [51]. Apelin-APJ systems are located in the central

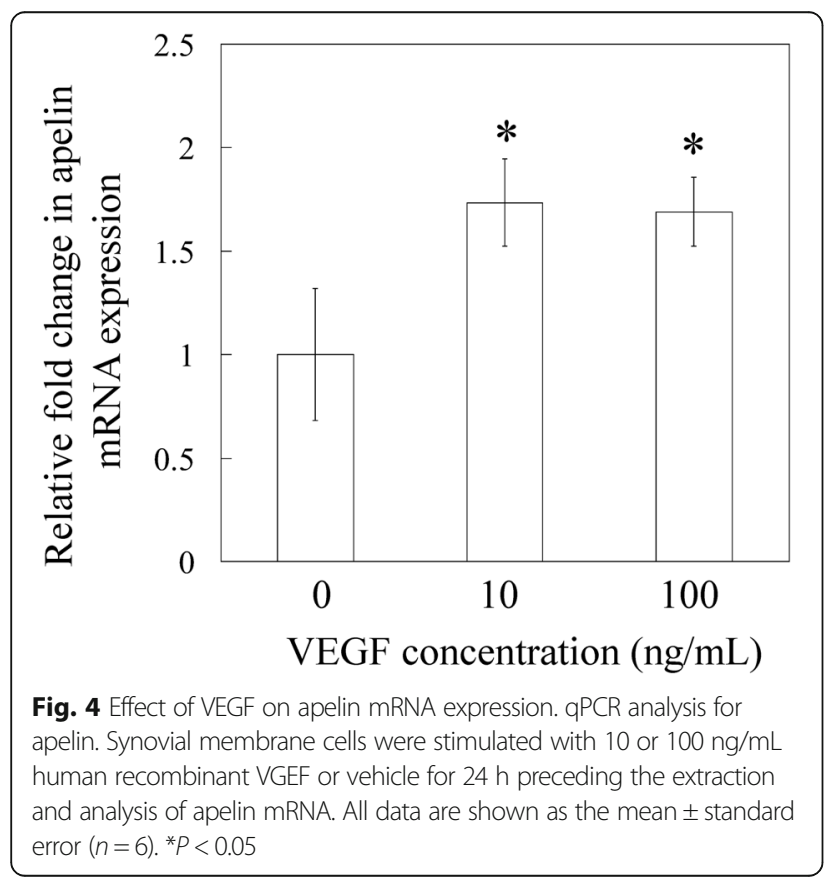

and peripheral nervous systems [52, 53]. In the central nervous system, apelin and its receptors have been detected in pain-associated regions. Previous studies have reported that intrathecal injection of apelin-13 (the isoform that binds most strongly to the APJ) induces hyperalgesia [21], and when "intrathecal administration of ML221, an APJ blocker, was used, this transiently reduced CCI-induced pain hypersensitivity" [43]. In addition, higher apelin concentrations in serum and SF were found in $\mathrm{OA}$ patients compared to non-OA patients [44]. Here, VEGF stimulated apelin mRNA and protein expression in SMCs, suggesting that further investigation of a direct link between apelin and pain may explain the mechanism underlying VEGF-induced OA pain.

A number of limitations of this study warrant mention. First, the absence of a non-KOA control patient population reduces the certainty of our results. Additional evaluations aimed at confirming whether VEGF levels are raised in the SMs of KOA patients compared to non-KOA patients are needed. Second, whether SMCs extracted from OA knees will behave the same as SMCs from healthy knees when treated with VEGF remains to be determined. Third, although our findings support the idea that altered VEGF levels in SMs are associated with KOA pain, whether a direct causative link exists between VEGF and apelin remains to be clarified. 
$\mathbf{a}$

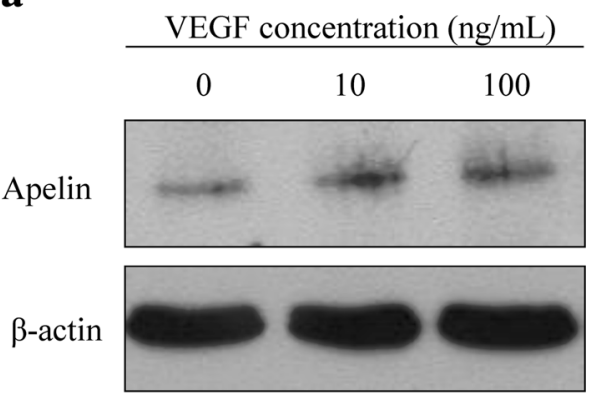

b

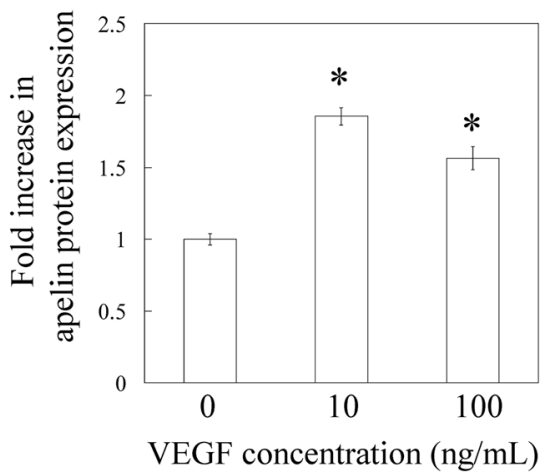

Fig. 5 Effect of VEGF on apelin protein expression. Western blotting analysis for apelin. Synovial membrane cells were stimulated with 10 or $100 \mathrm{ng} / \mathrm{mL}$ human recombinant VGEF or vehicle for $24 \mathrm{~h}$ preceding protein extraction and analysis of apelin protein. a Western blot of apelin and $\beta$-actin. $\mathbf{b}$ Densitometric analysis of apelin bands. All data are shown as the mean \pm standard error $(n=6)$. ${ }^{*}<0.05$ compared with the vehicle control

Finally, the relationship between apelin and pain in SMs was not determined.

\section{Conclusions}

Elevated VEGF expression in SMs was associated with an increase in pain in KOA patients with severe/strong pain. VEGF may regulate apelin expression in SMCs. The present findings suggest that altering the regulation of VEGF and apelin expression in SMs may represent a promising and suitable pharmaceutical strategy for the management of KOA pain.

\section{Abbreviations}

BCA: Bicinchoninic acid; BMI: Body mass index; CGRP: Calcitonin gene-related peptide; K/L: Kellgren/Lawrence; KOA: Knee osteoarthritis; NGF: Nerve growth factor; NSAIDs: Nonsteroidal anti-inflammatory drugs; OA: Osteoarthritis; PVDF: Polyvinylidene fluoride; SE: Standard error; SF: Synovial fluid; SM: Synovial membrane; SMCs: Synovial membrane cells; VAS: Visual analog scale; VEGF: Vascular endothelial growth factor

\section{Acknowledgements}

We thank Ms. Yuko Onuki for her assistance with real time PCR analysis. We thank Libby Cone, MD, MA, and Heidi Tran, PhD, from DMC Corp. (dmed.co.jp) for editing drafts of this manuscript.

\section{Funding}

This investigation was supported in part by a Kitasato University Research Grant for Young Researchers, Grant of Japan Orthopaedics and Traumatology Research Foundation, Inc. No. 373, JSPS KAKENHI Grant No. 18K09119, and research grants from the Parents' Association of Kitasato University School of Medicine.

\section{Availability of data and materials}

The datasets supporting the conclusions of this article are included within the article. The raw data can be requested from the corresponding author.

\section{Authors' contributions}

ST, KU and MT designed the study and performed the analysis of the data. ST and KU wrote the manuscript. ST, GI, TM, JA, DI, MM (Mukai), and MM (Miyagi) participated in the data collection, analysis, and interpretation. All authors read and approved the final manuscript.

\section{Ethics approval and consent to participate}

This study was approved by the Ethics Review Board of Kitasato University (reference number: KMEO B13-113). Written consent to participate was obtained from the all participants for the harvesting of their synovial tissue for use in this study.

\section{Consent for publication}

Not applicable

\section{Competing interests}

The authors declare that they have no competing interests.

\section{Publisher's Note}

Springer Nature remains neutral with regard to jurisdictional claims in published maps and institutional affiliations.

\section{Author details}

${ }^{1}$ Department of Orthopedic Surgery, Kitasato University School of Medicine, 1-15-1 Minami-ku Kitasato, Sagamihara City 252-0374, Japan. ${ }^{2}$ Department of Pathology, Kitasato University School of Medicine, 1-15-1 Minami-ku Kitasato, Sagamihara City 252-0374, Japan.

Received: 15 January 2018 Accepted: 11 June 2018

Published online: 26 June 2018

\section{References}

1. Ayis $S$, Dieppe $P$. The natural history of disability and its determinants in adults with lower limb musculoskeletal pain. J Rheumatol. 2009;36(3):583-91.

2. Dominick KL, Ahern FM, Gold CH, Heller DA. Health-related quality of life and health service use among older adults with osteoarthritis. Arthritis Rheum. 2004;51(3):326-31.

3. Hadler NM. Knee pain is the malady-not osteoarthritis. Ann Intern Med. 1992;116(7):598-9.

4. McAlindon TE, Cooper C, Kirwan JR, Dieppe PA. Determinants of disability in osteoarthritis of the knee. Ann Rheum Dis. 1993;52(4):258-62.

5. Guccione AA, Felson DT, Anderson JJ, Anthony JM, Zhang Y, Wilson PW, Kelly-Hayes M, Wolf PA, Kreger BE, Kannel WB. The effects of specific medical conditions on the functional limitations of elders in the Framingham study. Am J Public Health. 1994;84(3):351-8.

6. Johnsen SP, Larsson H, Tarone RE, McLaughlin JK, Norgard B, Friis S, Sorensen HT. Risk of hospitalization for myocardial infarction among users of rofecoxib, celecoxib, and other NSAIDs: a population-based case-control study. Arch Intern Med. 2005;165(9):978-84.

7. Whelton A. Renal and related cardiovascular effects of conventional and COX2-specific NSAIDs and non-NSAID analgesics. Am J Ther. 2000;7(2):63-74.

8. Giatromanolaki A, Sivridis E, Maltezos E, Athanassou N, Papazoglou D, Gatter KC, Harris AL, Koukourakis MI. Upregulated hypoxia inducible factor-1alpha 
and -2alpha pathway in rheumatoid arthritis and osteoarthritis. Arthritis Res Ther. 2003;5(4):R193-201.

9. Haywood L, McWilliams DF, Pearson Cl, Gill SE, Ganesan A, Wilson D, Walsh DA. Inflammation and angiogenesis in osteoarthritis. Arthritis Rheum. 2003;48(8):2173-7.

10. Jackson JR, Minton JA, Ho ML, Wei N, Winkler JD. Expression of vascular endothelial growth factor in synovial fibroblasts is induced by hypoxia and interleukin 1beta. J Rheumatol. 1997;24(7):1253-9.

11. Lambert C, Mathy-Hartert M, Dubuc JE, Montell E, Verges J, Munaut C, Noel A, Henrotin Y. Characterization of synovial angiogenesis in osteoarthritis patients and its modulation by chondroitin sulfate. Arthritis Res Ther. 2012;14(2):R58.

12. Corrado A, Neve A, Cantatore FP. Expression of vascular endothelial growth factor in normal, osteoarthritic and osteoporotic osteoblasts. Clin Exp Med. 2013;13(1):81-4.

13. Huh JE, Seo DM, Baek YH, Choi DY, Park DS, Lee JD. Biphasic positive effect of formononetin on metabolic activity of human normal and osteoarthritic subchondral osteoblasts. Int Immunopharmacol. 2010;10(4):500-7.

14. Neve A, Cantatore FP, Corrado A, Gaudio A, Ruggieri S, Ribatti D. In vitro and in vivo angiogenic activity of osteoarthritic and osteoporotic osteoblasts is modulated by VEGF and vitamin D3 treatment. Regul Pept. 2013;184:81-4.

15. Fay J, Varoga D, Wruck CJ, Kurz B, Goldring MB, Pufe T. Reactive oxygen species induce expression of vascular endothelial growth factor in chondrocytes and human articular cartilage explants. Arthritis Res Ther. 2006;8(6):R189

16. Mabey T, Honsawek S, Saetan N, Poovorawan Y, Tanavalee A, Yuktanandana P. Angiogenic cytokine expression profiles in plasma and synovial fluid of primary knee osteoarthritis. Int Orthop. 2014;38(9):1885-92.

17. Saetan N, Honsawek S, Tanavalee A, Yuktanandana P, Meknavin S, Ngarmukos S, Tanpowpong T, Parkpian V. Relationship of plasma and synovial fluid vascular endothelial growth factor with radiographic severity in primary knee osteoarthritis. Int Orthop. 2014;38(5):1099-104.

18. Sohn DH, Sokolove J, Sharpe O, Erhart JC, Chandra PE, Lahey LJ, Lindstrom TM, Hwang I, Boyer KA, Andriacchi TP, Robinson WH. Plasma proteins present in osteoarthritic synovial fluid can stimulate cytokine production via toll-like receptor 4. Arthritis Res Ther. 2012;14(1):R7

19. Ballara S, Taylor PC, Reusch P, Marme D, Feldmann M, Maini RN, Paleolog EM. Raised serum vascular endothelial growth factor levels are associated with destructive change in inflammatory arthritis. Arthritis Rheum. 2001;44(9):2055-64.

20. Cui RR, Mao DA, Yi L, Wang C, Zhang XX, Xie H, Wu XP, Liao XB, Zhou H, Meng JC, Yuan LQ, Liao EY. Apelin suppresses apoptosis of human vascular smooth muscle cells via APJ/PI3-K/Akt signaling pathways. Amino Acids. 2010;39(5):1193-200.

21. Lv S, Yang YJ, Hong S, Wang N, Qin Y, Li W, Chen Q. Intrathecal apelin-13 produced different actions in formalin test and tail-flick test in mice. Protein Pept Lett. 2013;20(8):926-31.

22. LV SY, Qin YJ, Wang NB, Yang YJ, Chen Q. Supraspinal antinociceptive effect of apelin-13 in a mouse visceral pain model. Peptides. 2012;37(1):165-70.

23. Perjes A, Skoumal R, Tenhunen O, Konyi A, Simon M, Horvath IG, Kerkela $R$ Ruskoaho H, Szokodi I. Apelin increases cardiac contractility via protein kinase Cepsilon- and extracellular signal-regulated kinase-dependent mechanisms. PLoS One. 2014;9(4):e93473.

24. Reaux A, Gallatz K, Palkovits M, Llorens-Cortes C. Distribution of apelinsynthesizing neurons in the adult rat brain. Neuroscience. 2002;113(3):653-62.

25. Reaux A, De MN, Skultetyova I, Lenkei Z, El MS, Gallatz K, Corvol P, Palkovits M, Llorens-Cortes C. Physiological role of a novel neuropeptide, apelin, and its receptor in the rat brain. J Neurochem. 2001;77(4):1085-96.

26. Smith TP, Schlenz AM, Schatz JC, Maitra R, Sweitzer SM. Modulation of pain in pediatric sickle cell disease: understanding the balance between endothelin mediated vasoconstriction and apelin mediated vasodilation. Blood Cells Mol Dis. 2015;54(2):155-9.

27. Than A, Cheng Y, Foh LC, Leow MK, Lim SC, Chuah YJ, Kang Y, Chen P. Apelin inhibits adipogenesis and lipolysis through distinct molecular pathways. Mol Cell Endocrinol. 2012;362(1-2):227-41.

28. Xu N, Wang H, Fan L, Chen Q. Supraspinal administration of apelin-13 induces antinociception via the opioid receptor in mice. Peptides. 2009;30(6):1153-7.

29. Giatromanolaki A, Sivridis E, Athanassou N, Zois E, Thorpe PE, Brekken RA, Gatter KC, Harris AL, Koukourakis IM, Koukourakis MI. The angiogenic pathway "vascular endothelial growth factor/flk-1(KDR)-receptor" in rheumatoid arthritis and osteoarthritis. J Pathol. 2001:194(1):101-8.

30. Nagai $T$, Sato M, Kobayashi M, Yokoyama M, Tani $Y$, Mochida J. Bevacizumab, an anti-vascular endothelial growth factor antibody, inhibits osteoarthritis. Arthritis Res Ther. 2014;16(5):427.

31. Kiguchi N, Kobayashi Y, Kadowaki Y, Fukazawa Y, Saika F, Kishioka S. Vascular endothelial growth factor signaling in injured nerves underlies peripheral sensitization in neuropathic pain. J Neurochem. 2014;129(1):169-78.

32. Lin J, Li G, Den X, Xu C, Liu S, Gao Y, Liu H, Zhang J, Li X, Liang S. VEGF and its receptor-2 involved in neuropathic pain transmission mediated by $\mathrm{P} 2 \mathrm{X}(2)(/)(3)$ receptor of primary sensory neurons. Brain Res Bull. 2010;83(5):284-91.

33. Liu S, Xu C, Li G, Liu H, Xie J, Tu G, Peng H, Qiu S, Liang S. Vatalanib decrease the positive interaction of VEGF receptor-2 and $\mathrm{P} 2 \mathrm{X} 2 / 3$ receptor in chronic constriction injury rats. Neurochem Int. 2012;60(6):565-72.

34. Malykhina AP, Lei Q, Erickson CS, Epstein ML, Saban MR, Davis CA, Saban R. VEGF induces sensory and motor peripheral plasticity, alters bladder function, and promotes visceral sensitivity. BMC Physiol. 2012;12:15.

35. Selvaraj D, Gangadharan V, Michalski CW, Kurejova M, Stosser S, Srivastava K Schweizerhof M, Waltenberger J, Ferrara N, Heppenstall P, Shibuya M, Augustin $\mathrm{HG}$, Kuner R. A functional role for VEGFR1 expressed in peripheral sensory neurons in Cancer pain. Cancer Cell. 2015;27(6):780-96.

36. Takano S, Uchida K, Miyagi M, Inoue G, Fujimaki H, Aikawa J, Iwase D, Minatani A, Iwabuchi K, Takaso M. Nerve growth factor regulation by TNFalpha and IL-1beta in synovial macrophages and fibroblasts in osteoarthritic mice. J Immunol Res. 2016;2016:5706359.

37. Takano S, Uchida K, Miyagi M, Inoue G, Aikawa J, Fujimaki H, Minatani A, Sato M, Iwabuchi K, Takaso M. Synovial macrophage-derived IL-1beta regulates the calcitonin receptor in osteoarthritic mice. Clin Exp Immunol. 2016;183(1):143-9.

38. Takano S, Uchida K, Inoue G, Miyagi M, Aikawa J, Iwase D, Iwabuchi K, Matsumoto T, Satoh M, Mukai M, Minatani A, Takaso M. Nerve growth factor regulation and production by macrophages in osteoarthritic synovium. Clin Exp Immunol. 2017;190:235-43.

39. Takano S, Uchida K, Inoue G, Minatani A, Miyagi M, Aikawa J, Iwase D, Onuma K, Mukai M, Takaso M. Increase and regulation of synovial calcitonin gene-related peptide expression in patients with painful knee osteoarthritis. J Pain Res. 2017;10:1099-104.

40. Tatemoto K, Hosoya M, Habata Y, Fujii R, Kakegawa T, Zou MX, Kawamata Y, Fukusumi S, Hinuma S, Kitada C, Kurokawa T, Onda H, Fujino M. Isolation and characterization of a novel endogenous peptide ligand for the human APJ receptor. Biochem Biophys Res Commun. 1998;251(2):471-6.

41. Kunduzova O, Alet N, esque-Touchard N, Millet L, Castan-Laurell I, Muller C, Dray C, Schaeffer P, Herault JP, Savi P, Bono F, Valet P. Apelin/APJ signaling system: a potential link between adipose tissue and endothelial angiogenic processes. FASEB J. 2008:22(12):4146-53.

42. Kojima Y, Quertermous T. Apelin-APJ signaling in retinal angiogenesis Arterioscler Thromb Vasc Biol. 2008;28(10):1687-8.

43. Xiong $\mathrm{Q}$, He W, Wang H, Zhou J, Zhang Y, He J, Yang C, Zhang B. Effect of the spinal apelinAPJ system on the pathogenesis of chronic constriction injuryinduced neuropathic pain in rats. Mol Med Rep. 2017;16:1223-31.

44. Hu PF, Tang JL, Chen WP, Bao JP, Wu LD. Increased apelin serum levels and expression in human chondrocytes in osteoarthritic patients. Int Orthop. 2011;35(9):1421-6.

45. Minatani A, Uchida K, Inoue G, Takano S, Aikawa J, Miyagi M, Fujimaki H, Iwase D, Onuma K, Matsumoto T, Takaso M. Activation of calcitonin gene-related peptide signaling through the prostaglandin E2-EP1/EP2/EP4 receptor pathway in synovium of knee osteoarthritis patients. J Orthop Surg Res. 2016;11(1):117.

46. Collins SL, Moore RA, McQuay HJ. The visual analogue pain intensity scale: what is moderate pain in millimetres? Pain. 1997;72(1-2):95-7.

47. rendt-Nielsen $L$, Nie $H$, Laursen MB, Laursen BS, Madeleine $P$, Simonsen $O H$, Graven-Nielsen T. Sensitization in patients with painful knee osteoarthritis. Pain. 2010;149(3):573-81.

48. Uchida K, Takano S, Matsumoto T, Nagura N, Inoue G, Itakura M, Miyagi M, Aikawa J, Iwase D, Minatani A, Fujimaki H, Takaso M. Transforming growth factor activating kinase 1 regulates extracellular matrix degrading enzymes and pain-related molecule expression following tumor necrosis factor-alpha stimulation of synovial cells: an in vitro study. BMC Musculoskelet Disord. 2017;18(1):283.

49. Nesic O, Sundberg LM, Herrera JJ, Mokkapati VU, Lee J, Narayana PA. Vascular endothelial growth factor and spinal cord injury pain. J Neurotrauma. 2010;27(10):1793-803. 
50. Kasai A, Shintani N, Oda M, Kakuda M, Hashimoto H, Matsuda T, Hinuma S, Baba A. Apelin is a novel angiogenic factor in retinal endothelial cells. Biochem Biophys Res Commun. 2004;325(2):395-400.

51. Zhao T, Lu Q, Tao Y, Liang XY, Wang K, Jiang YR. Effects of apelin and vascular endothelial growth factor on central retinal vein occlusion in monkey eyes intravitreally injected with bevacizumab: a preliminary study. Mol Vis. 2011;17:1044-55

52. Kawamata $Y$, Habata Y, Fukusumi S, Hosoya M, Fujii R, Hinuma S, Nishizawa N, Kitada C, Onda H, Nishimura O, Fujino M. Molecular properties of apelin: tissue distribution and receptor binding. Biochim Biophys Acta. 2001; 1538(2-3):162-71.

53. Medhurst AD, Jennings CA, Robbins MJ, Davis RP, Ellis C, Winborn KY, Lawrie KW, Hervieu G, Riley G, Bolaky JE, Herrity NC, Murdock P, Darker JG. Pharmacological and immunohistochemical characterization of the APJ receptor and its endogenous ligand apelin. J Neurochem. 2003; 84(5):1162-72

Ready to submit your research? Choose BMC and benefit from:

- fast, convenient online submission

- thorough peer review by experienced researchers in your field

- rapid publication on acceptance

- support for research data, including large and complex data types

- gold Open Access which fosters wider collaboration and increased citations

- maximum visibility for your research: over $100 \mathrm{M}$ website views per year

At BMC, research is always in progress.

Learn more biomedcentral.com/submissions 